\title{
Continuous and catalyst free synthesis of graphene sheets in
}

\author{
thermal plasma jet
}

\begin{abstract}
Maciej Fronczak ${ }^{1 *}$, Péter Fazekas ${ }^{2}$, Zoltán Károly $^{2}$, Bartosz Hamankiewicz ${ }^{1}$ and Michał Bystrzejewski ${ }^{1}$
\end{abstract}

\footnotetext{
${ }^{1}$ Faculty of Chemistry, University of Warsaw, Pasteur 1 str. 02-093 Warsaw, Poland

${ }^{2}$ Institute of Materials and Environmental Chemistry, Research Centre for Natural Sciences, Hungarian Academy of Sciences, Magyar tudósok körútja 2, 1117 Budapest, Hungary
} 


\begin{abstract}
Herein we present a continuous and catalyst free method for the synthesis of graphene sheets from aliphatic alcohols in a radiofrequency thermal plasma jet. Nine aliphatic linear alcohols (ethanol-decanol) were tested as possible precursors for the massive production of graphene sheets. Moreover, additional tests were also carried out with the inclusion of gaseous oxygen in order to promote the formation of graphene and to eliminate the unwanted carbon byproducts. The obtained materials were investigated by electron microscopy, Raman and infrared spectroscopy. The thermal stability of products was also evaluated using thermogravimetry. The surface chemistry features were analyzed using acid-base titration and X-ray photoelectron and IR spectroscopy. Finally, the adsorption performance of graphene sheets was tested in the removal of 4-chlorophenol from aqueous solutions. The highest content of graphene sheets was found in the product obtained from ethanol with the production rate of ca. $1.5 \mathrm{~g} / \mathrm{h}$. The plasma processing of higher alcohols yielded a mixture of graphene sheets and spherical carbon nanoparticles.
\end{abstract}

Key words: graphene sheets, aliphatic alcohols, radio frequency thermal plasma, continuous synthesis 


\section{Introduction}

The first described methods of synthesis of graphene materials was discovered independently by two research groups at the beginning of twenty first century. Graphene was obtained via thermal desorption of silicon from Si-terminated single crystal of silicon carbide in ultrahigh vacuum (ca. $10^{-8} \mathrm{~Pa}$ ) by electron bombardment [1]. In the second case, the mechanical exfoliation of pyrolytic graphite was applied [2]. Nowadays, the exfoliation of graphite can be carried out using alkali metals, e.g. potassium [3] or lithium [4]. Moreover, graphite can be also exfoliated in carbon arc discharge under hydrogen atmosphere [5-6]. Furthermore, the exfoliation can be also carried out via ultrasound treatment of graphite in aqueous solutions of surfactants [7-10] or in supercritical $\mathrm{CO}_{2} / \mathrm{H}_{2} \mathrm{O}$ mediums [11]. The synthesis of graphene materials via exfoliation route is time-consuming (24-48 h) and do not lead to large amounts of the products at the laboratory scale. The current state of the art on graphene synthesis includes also chemical vapor deposition (CVD) onto silicon carbide [1214] or copper [15]. It is also possible to obtain graphene via plasma-assisted CVD [16-17]. These processes require the use of an appropriate catalyst. Graphene materials can be also synthesized via reduction of graphene oxides using (i) chemical reducers [18-20], (ii) electrochemical processes [21-24] and (iii) thermal routes [6, 25]. Finally, graphene materials were also obtained via combustion synthesis [26-28].

Graphene, few-layer graphene and graphene sheets exhibit unique physical and chemical properties and have a high potential to be applied in high-tech devices and applications. For example, graphene-based membranes are permeable for water vapor, but not for other liquids or gases [29]. This phenomenon can be used to preconcentrate aqueous solutions and in consequence to obtain pure water. Another possible application of graphene materials, taking advantage of their electrochemical properties, is to fabricate ultrathin electrodes, which can be used as the electrochemical sensor of dyes [30], hormones (for 
example serotonin) or glucose, which is very important in diabetics diagnostics [31]. Recently, Bahadır and Sezgintürk in their review [32] described a few-layer graphene based sensor dedicated to determine biomolecules, e.g. enzymes and DNA. Graphene-based materials and their composites have promising scope in energy storage, for instance as a component of rechargeable lithium batteries [33], or in construction of supercapacitors [3435].

In this work, a novel approach to the synthesis of graphene sheets is investigated. We used oxygen-containing compounds, namely various aliphatic alcohols, as promising and lowcost precursors of graphene sheets. Another goal of the research was to study the role of gaseous oxygen added to the plasma gas on the formation of graphene sheets. The presence of oxygen and various oxides has a great influence on the growth of carbon nanomaterials (graphene and carbon-encapsulated magnetic nanoparticles) during thermal plasma synthesis [36-38]. It is noteworthy, that the use of in-flight plasma processing allows to carry out the experiment in a continuous manner and without the necessity of using the catalyst. A similar approach, in a microwave plasma system has already been published [17; 39-40]. However, in these papers only two carbon precursors (methanol and ethanol) were tested and the process was assisted by the presence of a catalyst system. Nevertheless, the obtained products were inhomogeneous, as they contained graphene materials and multi-wall carbon nanotubes. Our work is focused on the systematic studies on the plasma processing of a wide range of aliphatic alcohols without the presence of catalyst as possible precursors of graphene sheets. Amirov et al. studied the decomposition of hydrocarbons in the direct current thermal plasma jet without catalyst and obtained porous multilayer graphene materials [41]. Graphene sheets were obtained from ethanol by Dato et al. [42-43] in the microwave plasma system. In these works the catalyst was not used to promote the growth of few-layer graphene. 


\section{Materials and methods}

\subsection{Chemicals}

Aliphatic n-alcohols (ethanol- decanol), sodium hydroxide and hydrochloric acid were purchased from Avantor Performance Materials Poland. The plasma gases (Ar $99.996 \%$, He $99.999 \%$ purity) were from Messer Hungarogáz Kft. (Hungary). 4-chlorophenol (>99 \%) was purchased from Sigma Aldrich. Potassium bromide (IR grade) was from Across Organics.

Sodium hydroxide solution $\left(0.05 \mathrm{~mol} \cdot \mathrm{dm}^{-3}\right)$ and hydrochloric acid solution $\left(0.1 \mathrm{~mol} \cdot \mathrm{dm}^{-3}\right)$ were prepared using volumetric stock standard solutions. The working solutions of 4-chlorophenol were prepared by diluting the stock solution $\left(1000 \mathrm{mg} \cdot \mathrm{dm}^{-3}\right)$ in volumetric flasks.

\subsection{Plasma decomposition of alcohols}

The decomposition of aliphatic n-alcohols was carried out in an RF thermal plasma system, which consisted of an RF inductively coupled plasma torch (TEKNA PL-35) connected to a high frequency (4-5 MHz) LEPEL generator, a reactor, a cyclone, a filter unit and a vacuum pump (see Supplementary Data, Figure S1 and papers [44-45]). The doublewall, water cooled cylindrical reactor was made of stainless steel with the inner diameter of $19.7 \mathrm{~cm}$ and length of $121.6 \mathrm{~cm}$. The delivered net power was $25 \pm 1 \mathrm{~kW}$. The alcohol precursors were delivered by a peristaltic pump (Masterflex) to an atomizer probe $(2.16 \mathrm{~mm}$ inner diameter), and was fed coaxially into the hottest part of the plasma jet with the feeding rate of $7.5 \pm 0.5 \mathrm{~cm}^{3} \cdot \mathrm{min}^{-1}$. Argon with the flow rate of $7.5 \mathrm{dm}^{3} \cdot \mathrm{min}^{-1}$ was used for atomization. The experiments were carried out under the atmosphere of argon and helium. The flow rates were as follows: sheath gas- argon $40 \mathrm{dm}^{3} \cdot \mathrm{min}^{-1}$ and helium $27 \mathrm{dm}^{3} \cdot \mathrm{min}^{-1}$, plasma gas- argon $15.5 \mathrm{dm}^{3} \cdot \mathrm{min}^{-1}$. Two additional tests with n-decanol were also carried out 
under atmosphere enriched with $1 \%\left(1 \mathrm{dm}^{3} \cdot \mathrm{min}^{-1}\right)$ and $5 \%\left(4.75 \mathrm{dm}^{3} \cdot \mathrm{min}^{-1}\right)$ of oxygen added directly to the plasma gas. The experiments were conducted at the pressure of $70 \pm 3 \mathrm{kPa}$.

\subsection{Characterization of the products}

The products, in the form of black and dusty powder were collected by a brush from the inner walls of the reactor and then weighted. The morphology of the carbon products was investigated using scanning (SEM; Zeiss Merlin) and transmission (TEM; Zeiss Libra 120) electron microscopy. The Raman spectra of the solid samples were acquired using a Jobin Yvon-Spex T64000 Raman spectrometer equipped an Ar-ion excitation laser (514.5 nm). The spectra were registered in the range of $800-3000 \mathrm{~cm}^{-1}$. The infrared spectra were recorded using a Thermo Fisher Scientific Nicolet spectrometer. A petite amount (ca. $1 \mathrm{mg}$ ) of a sample was mixed with $300 \mathrm{mg}$ of potassium bromide, then, the mixtures were pressed into pellets using a laboratory hydraulic press. The spectra were acquired in the transmission mode in the spectral range of $400-4000 \mathrm{~cm}^{-1}$

Thermal stability of carbon products obtained in the particular tests was studied by thermogravimetry (TGA) using a TA Q50 instrument. The measurements were performed under oxidizing atmosphere $\left(\mathrm{N}_{2} / \mathrm{O}_{2} 95 / 5\right.$ vol. \%) with the heating rate of $10{ }^{\circ} \mathrm{C} \cdot \mathrm{min}^{-1}$.

The Boehm titration method [46-49] was used to determine the content of surface acidic groups. $50 \mathrm{mg} \pm 1 \mathrm{mg}$ of the material was put into $50 \mathrm{~cm}^{3}$ of sodium hydroxide solution $\left(0,05 \mathrm{~mol} \cdot \mathrm{dm}^{-3}\right)$ at $23 \pm 1{ }^{\circ} \mathrm{C}$. After 24 hours the concentration of $\mathrm{NaOH}$ was determined by potentiometric analysis using an automatic Metrohm Titrando 888 titrator.

The XPS spectra were acquired using a Kratos Axis Supra 5 spectrometer with monochromatic $\mathrm{Al} \mathrm{K} \alpha$ radiation $(1486.6 \mathrm{eV})$. The samples were placed into brass holders.

The adsorption properties of the obtained materials were evaluated for 4-chlorophenol. The tests were carried out at $23^{\circ} \mathrm{C} \pm 1.50 \mathrm{mg}$ of the studied material was added to $50 \mathrm{~cm}^{3}$ of 4-chlorophenol aqueous solution in a plastic vial and shaken for at least $6 \mathrm{~h}$. Afterwards, a 
Shimadzu UV-2401 PC spectrometer was used to determine the equilibrium concentration of 4-chlorophenol.

\section{Results and discussion}

\subsection{Experimental results}

The obtained conversion yields (calculated according to Formula 1) are listed for each experiment in Table 1 . The lowest conversion yield (0.003) is found for ethanol. The yield is higher for other alcohols and rises nearly linearly with decreasing of the oxygen to carbon ratio (Figure 1). It was an expected finding because the available amount of graphite is higher for higher aliphatic alcohols [50]. Accordingly, the highest yield of 0.061 was obtained for decanol. Nevertheless, most of the injected liquid precursor was not transformed to the solid products and left the reaction zone in the form of various gaseous species, such as carbon monoxide, acetylene and other hydrocarbons [44-45]. Figure 2 presents the relation between the product formation rate (i.e. the amount of solid products which is produced in a unit time) and the oxygen to carbon ratio for all used alcohols. The patterns in Figures 1 and 2 are similar, because the alcohol feeding rate was almost the same in all experiments $\left(7.5 \pm 0.5 \mathrm{~cm}^{3} \cdot \mathrm{min}^{-1}\right)$. The similarity also stems from the comparable density of the tested alcohols. The inclusion of oxygen into the plasma jet in the experiments with decanol also diminishes the conversion yield and the product formation yield. Nevertheless, the direct comparison of the similar $\mathrm{O} / \mathrm{C}$ ratio $(0.315)$ in the test with oxygen and decanol (Test 10) with pure propanol (0.333; Test 8$)$ shows that the added extra oxygen has lower activity. This is because we observe higher conversion yield and larger product formation yield in the test with decanol and oxygen. The same finding comes from Test 11 in which the $\mathrm{O} / \mathrm{C}$ ratio was the highest, and despite of this fact the conversion yield has not markedly decreased.

$$
\text { Conversion yield }=\frac{\text { Product formation rate }\left(g \cdot h^{-1}\right)}{\text { Feeding rate }\left(g \cdot h^{-1}\right)}(\text { Formula } 1)
$$


Table 1.Operational parameters and conversion yield.

\begin{tabular}{|c|c|c|c|c|}
\hline Test & $\begin{array}{c}\text { Alcohol and O/C ratio (in the } \\
\text { bracket) }\end{array}$ & $\begin{array}{c}\text { Feeding rate } \\
\left(\mathrm{g} \cdot \mathrm{h}^{-1}\right)\end{array}$ & $\begin{array}{c}\text { Product formation rate } \\
\left(\mathrm{g} \cdot \mathrm{h}^{-1}\right)\end{array}$ & $\begin{array}{c}\text { Conversion yield } \\
\left(\mathrm{g} \cdot \mathrm{g}^{-1}\right)\end{array}$ \\
\hline 1 & decanol $(0.100)$ & 344 & 20,9 & 0,061 \\
\hline 2 & nonanol $(0.111)$ & 354 & 21,3 & 0,060 \\
\hline 3 & octanol $(0.125)$ & 359 & 12,0 & 0,033 \\
\hline 4 & heptanol $(0.143)$ & 360 & 15,9 & 0,044 \\
\hline 5 & hexanol $(0.167)$ & 358 & 11,2 & 0,031 \\
\hline 6 & pentanol $(0.200)$ & 380 & 14,6 & 0,038 \\
\hline 7 & butanol $(0.250)$ & 362 & 10,8 & 0,029 \\
\hline 8 & propanol $(0.333)$ & 361 & 5,3 & 0,015 \\
\hline 9 & ethanol $(0.500)$ & 429 & 1,5 & 0,003 \\
\hline 10 & decanol $+\mathrm{O}_{2} 1 \%(0.315)$ & 377 & 20,6 & 0,055 \\
\hline 11 & decanol $+\mathrm{O}_{2} 5 \%(1.013)$ & 398 & 10,7 & 0,027 \\
\hline
\end{tabular}

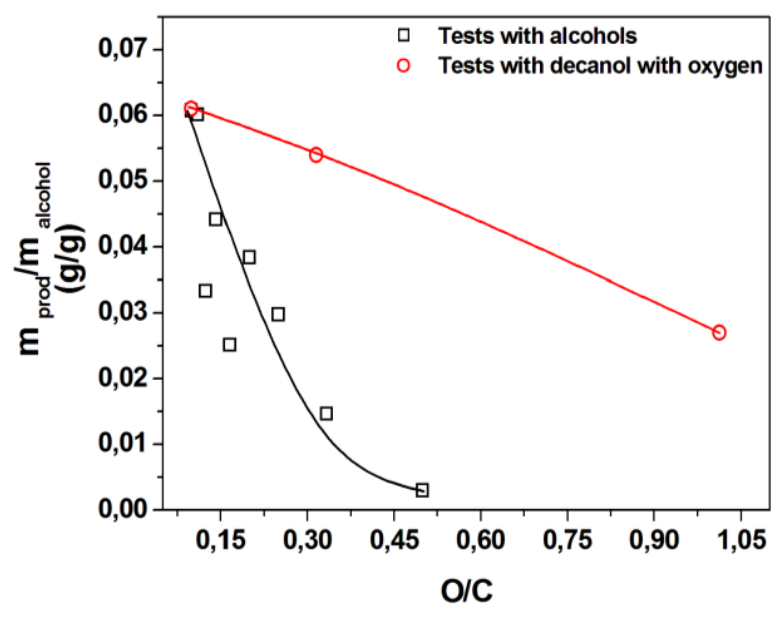

Figure 1. Relation between conversion yield of alcohols to solid products and oxygen to carbon ratio of alcohols. The solid curves are only to guide the eye. 


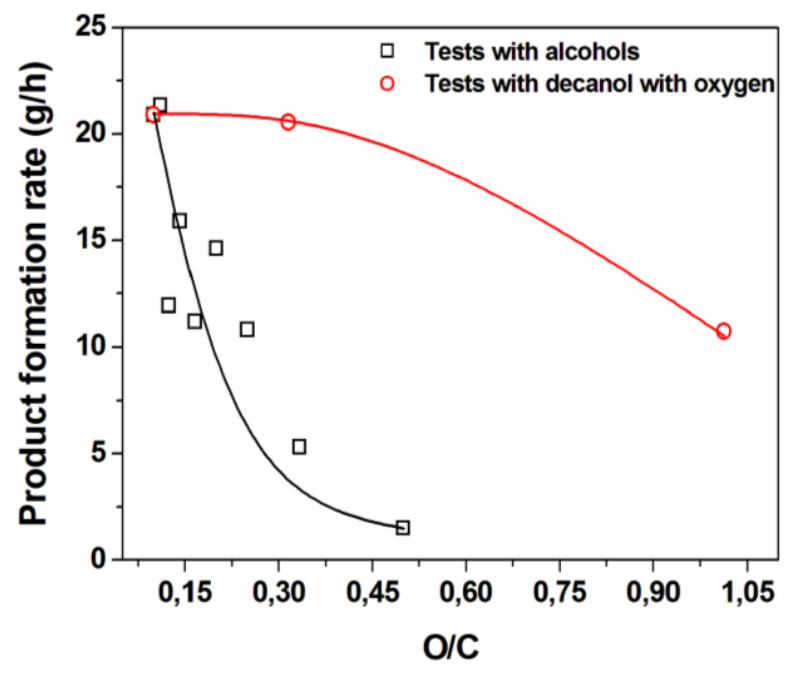

Figure 2. Relation between product formation rate to oxygen to carbon ratio in applied alcohols. The solid curves are only to guide the eye.

\subsection{Morphology of products}

The SEM images of products obtained from C3-C10 alcohols are shown in Figure 3. In each case, the products contain flakes and some spherical particles, which are similar to carbon black. The analysis of the images suggests that the fraction of spherical particles increases in the products obtained from higher aliphatic alcohols. On the other hand the fraction of flakes (typical for graphene sheets) is the highest for propanol and the lowest for decanol. The images of the products obtained from decanol with and without the inclusion of oxygen are shown in Figure 4. It can be seen, that the addition of oxygen does not substantially influence the overall morphology of the products. The material synthesized with the highest content of gaseous oxygen (Test 11) still contains flakes and nanoparticles. This finding shows that the inclusion of $\mathrm{O}_{2}$ does not improve the selectivity of the synthesis process. 

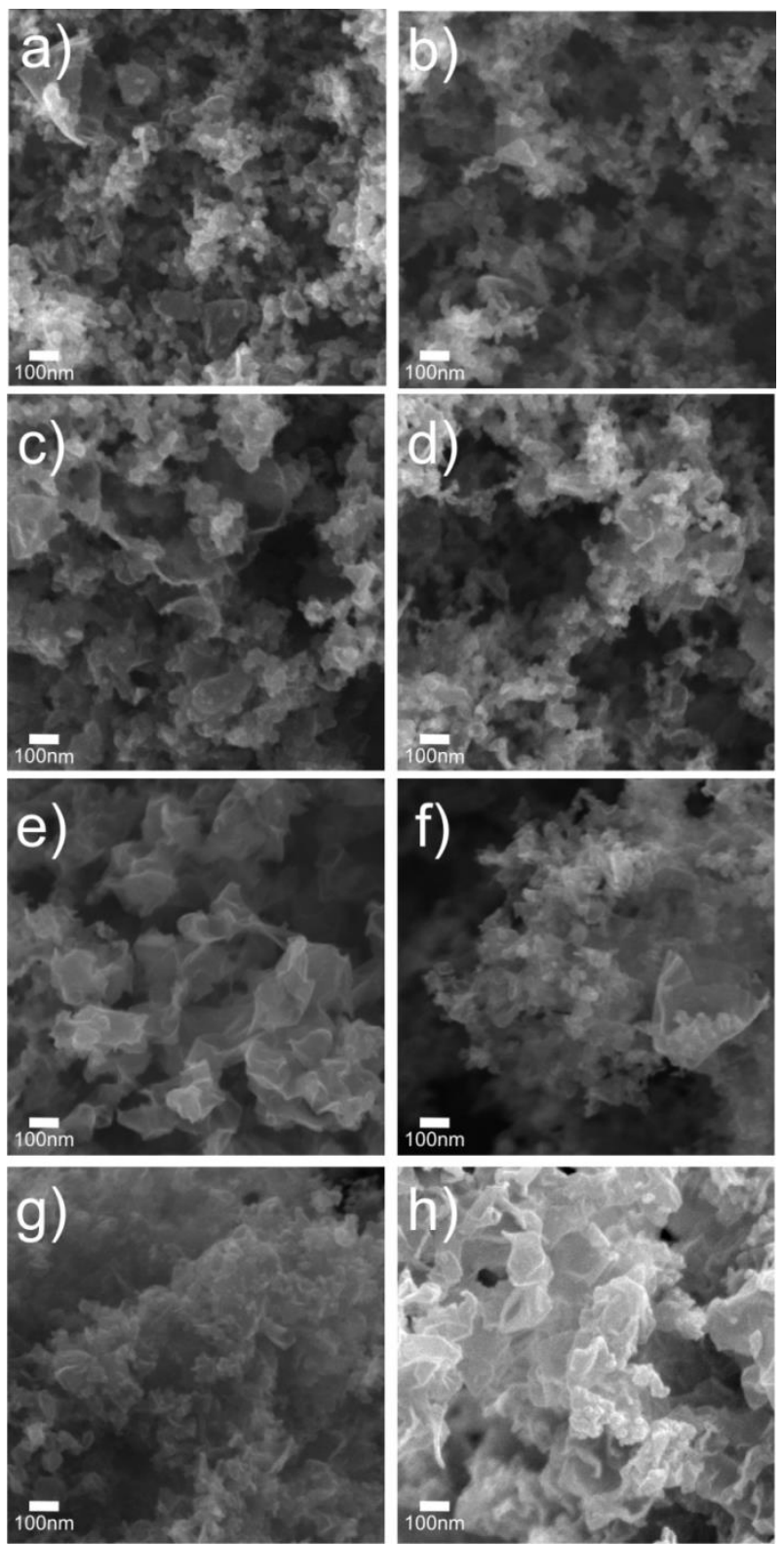

Figure 3. SEM images of products obtained via plasma decomposition of

a) decanol b) nonanol c) octanol d) heptanol e) hexanol f) pentanol g) butanol h) propanol. 

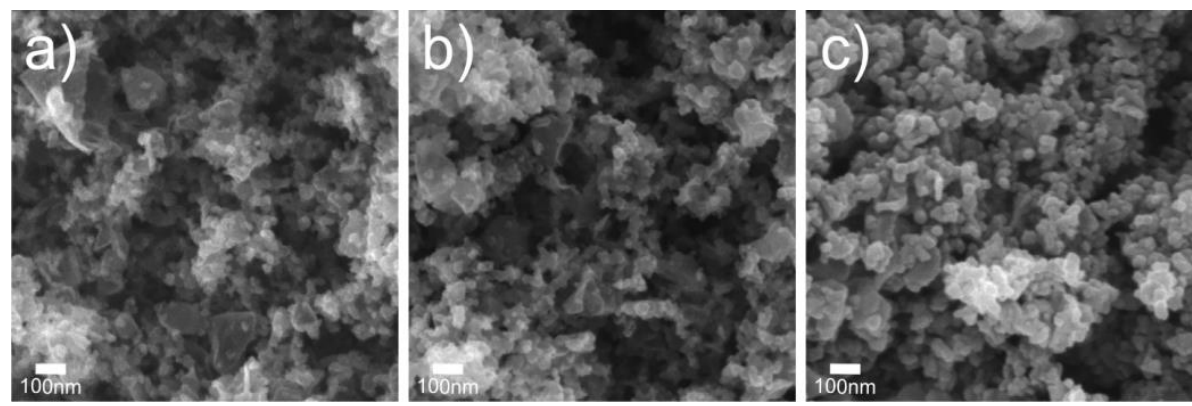

Figure 4. SEM images of products obtained via plasma decomposition of decanol:

a) Test $1\left(0 \% \mathrm{O}_{2}\right)$, b) Test10 $\left(1 \% \mathrm{O}_{2}\right)$, c) Test $11\left(5 \% \mathrm{O}_{2}\right)$.

The TEM images for the products obtained from various alcohols are shown in Figures 5 and 6. The TEM inspection is consistent with the SEM images, i.e. the products are comprised of spherical nanoparticles and graphene flakes. The spherical particles are semiporous and their diameter is between 10 and $40 \mathrm{~nm}$. Their morphology resembles the features of carbon black. The lateral size of graphene flakes is between 50 and $200 \mathrm{~nm}$. The analysis of the presented images draws a conclusion that the relative content of graphene flakes increases with the increase of the $\mathrm{O} / \mathrm{C}$ ratio. On the other hand the amount of spherical particles reduces with increasing the $\mathrm{O} / \mathrm{C}$ ratio and the lowest amount is found in the products obtained from propanol and butanol. The inclusion of gaseous oxygen (Tests 10 and 11) does not improve the selectivity of the process (Figure 6). In this case the relative content of graphene flakes is on a similar level in comparison to the product obtained from pure decanol (Test 1). Interestingly, the amount of spherical particles diminishes with increasing the gaseous oxygen flow rate (Figure $6 \mathrm{~b}$ and $6 \mathrm{c}$ ). Moreover, their diameter is slightly lower in comparison to Test 1 . This observations suggests that the gaseous oxygen partially etches the as-formed spherical particles and reduces their size. Additionally the inclusion of oxygen causes the formation of highly graphitized solid and hollow ellipsoidal particles with the size of 100-150 $\mathrm{nm}$. 

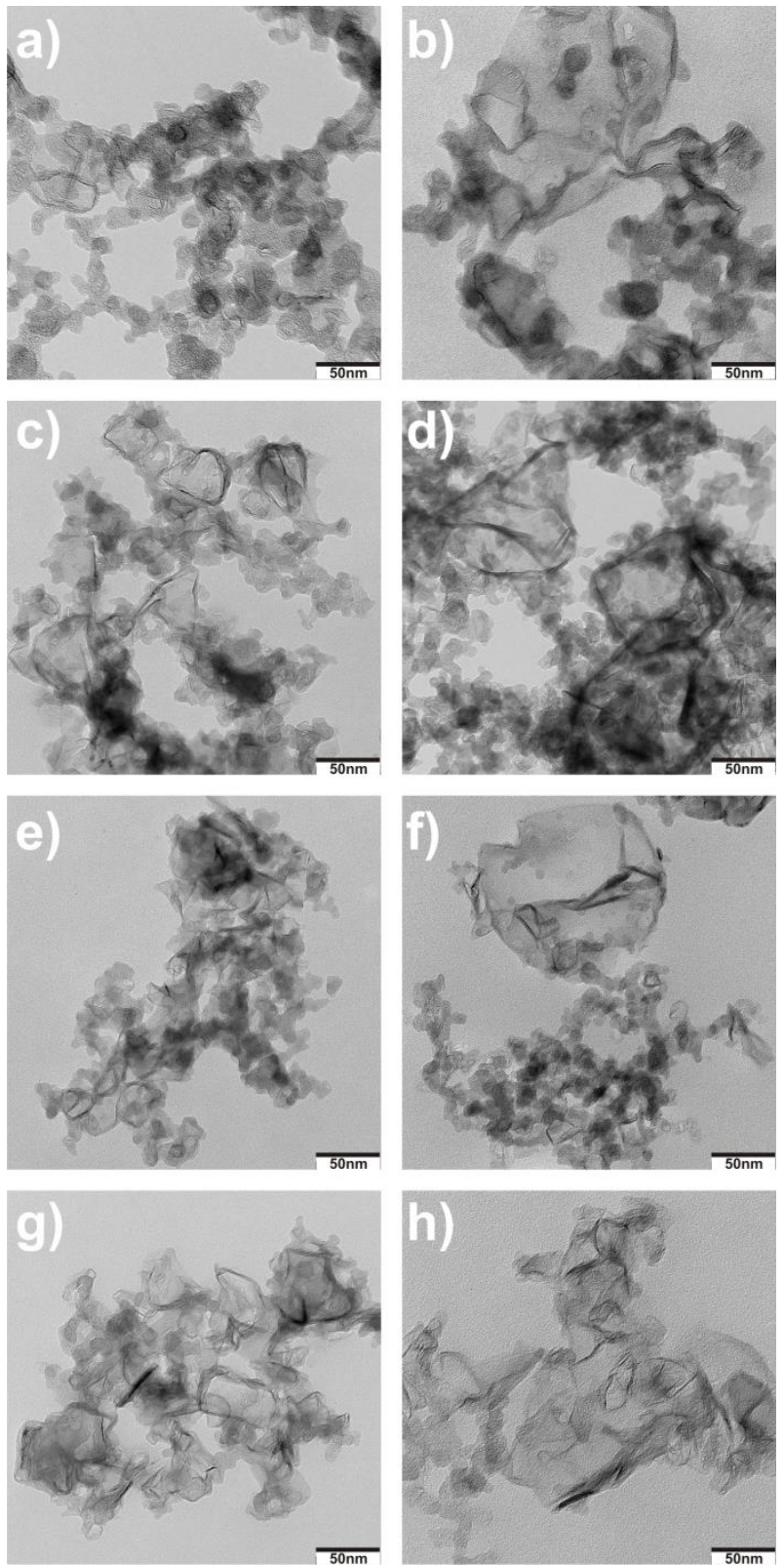

Figure 5. TEM images of the products obtained via plasma decomposition of

a) decanol b) nonanol c) octanol d) heptanol e) hexanol f) pentanol g) butanol h) propanol. 

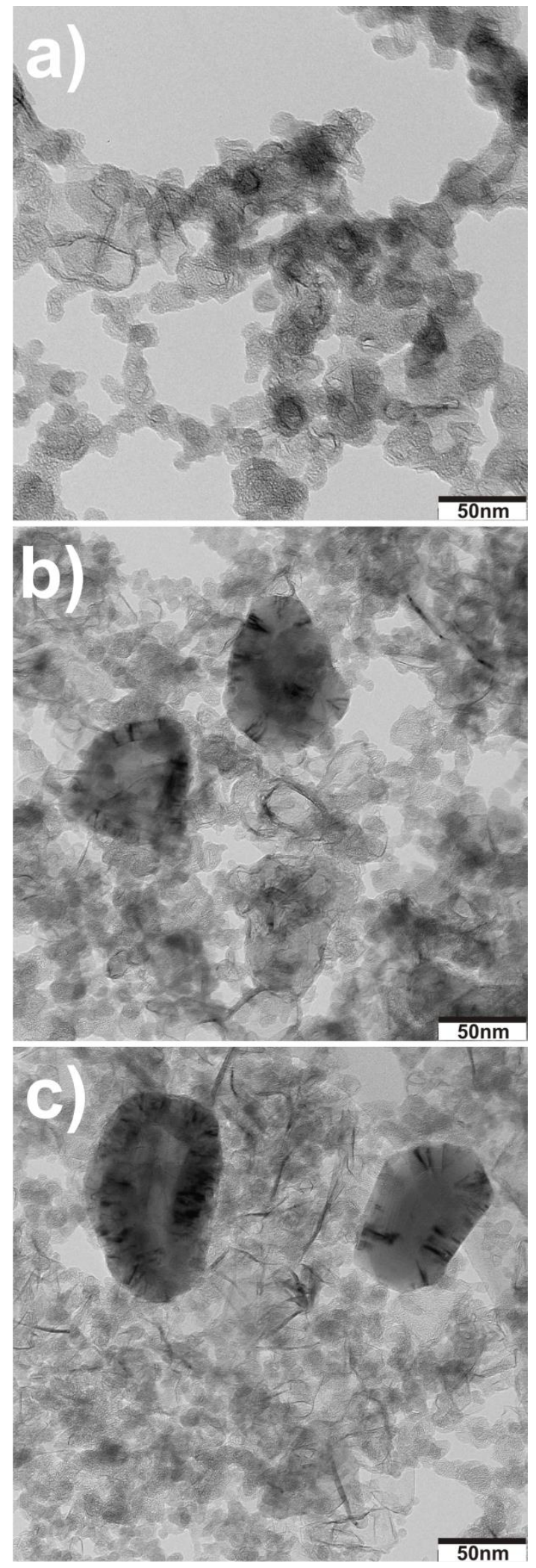

Figure 6. TEM images of products obtained via plasma decomposition of decanol:

a) Test $1\left(0 \% \mathrm{O}_{2}\right)$, b) Test $10\left(1 \% \mathrm{O}_{2}\right)$, c) Test $11\left(5 \% \mathrm{O}_{2}\right)$. 
The most interesting results are found for the plasma decomposition of ethanol. The representative SEM images are shown in Figure 7. The product is very homogenous and exclusively comprises of flake-like structures. Further analysis via TEM (Figure8) confirms that these flakes are graphene sheets. The lateral size of graphene sheets is between 50 and $200 \mathrm{~nm}$. The thickness of graphene sheets was roughly evaluated directly from the bending parts and is found to be between 3 to $10 \mathrm{~nm}$, which corresponds to ca. 10-30 graphene layers (please see Figure S2 in Supplementary Data). Rincón et al. [40] studied the microwave plasma decomposition of ethanol and obtained inhomogeneous products containing carbon nanotubes and graphene-like structures. Dato et al. [42-43], contrary to work [40], demonstrated the processing of ethanol in microwave plasma (with higher values of thedelivered power, i.e. $450-1050 \mathrm{~W}$ ) yields the homogenous product which comprises fewlayer graphene only. Our finding undoubtedly demonstrates that the processing of ethanol (without any catalyst) in the radio frequency thermal plasma jet yields pure and homogenous product and shows that ethanol is the best precursor for the continuous synthesis of graphene sheets. The consistency of our results and the data from works [42-43] draws a conclusion that the selective synthesis is possible only when the high enough power is delivered to the system. According to the operation data the minimum energy consumption rate to reach the selective synthesis is found to be $30 \mathrm{Wh} \cdot \mathrm{g}^{-1}$ and $58 \mathrm{Wh} \cdot \mathrm{g}^{-1}$ for the microwave and RF thermal plasma, respectively. 


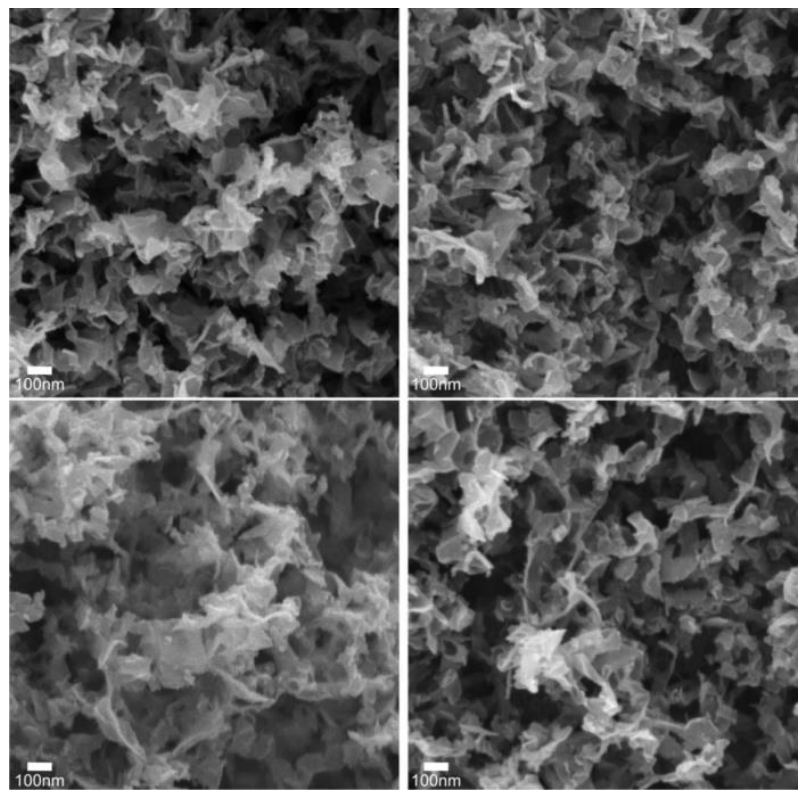

Figure 7. SEM images of the products obtained via plasma decomposition of ethanol.

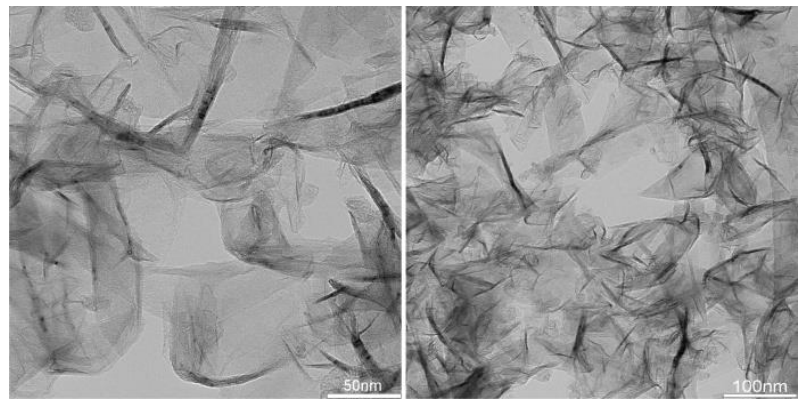

Figure 8. TEM images of the products obtained via plasma decomposition of ethanol.

The formation mechanism of carbon materials from various organic precursors in thermal plasma has been described in papers by Dato et al. [43] and Frenklach [51]. In general, acetylene $\left(\mathrm{C}_{2} \mathrm{H}_{2}\right)$, propargyl $\left(\mathrm{C}_{3} \mathrm{H}_{3}\right)$ and other radicals (which originate from the plasma decomposition of an organic precursor) collide in the colder parts of the reactor, and this phenomenon results in formation of dimers, trimers and larger clusters. The condensation of these species also leads to create aromatic rings and cyclic hydrocarbons. These processes terminates with the formation of soot particles comprising large polycyclic aromatic hydrocarbons molecules. These authors also show that the decomposition of alcohols higher than ethanol results in various carbon nanomaterials. This is because the amount of available 
carbon in the reactor is relatively high and it causes multiple collisions of the molecules during the formation of the products. This effect results in the formation of defected PAH molecules, which can form e.g. spherical particles. In the case of ethanol, the amount of carbon is optimal and the selectivity of the process is the highest. This formation mechanism is consistent with our observations. As it follows from Table 1 the feeding rate of all precursors is in the same range, what may suggest that the amount of the carbon precursor which is introduced to the plasma jet in on a similar level. This is not true, because the presence of oxygen results in formation of carbon monoxide and various hydrocarbons and finally changes the available amount of carbon in the plasma. The amount of the carbon available from 100 grams of the specified precursor has been calculated using a FactSage thermodynamic package $(\mathrm{p}=100 \mathrm{kPa}, \mathrm{T}=3000 \mathrm{~K})$. The results are shown in Figure 9. It is evident that the amount of available carbon from higher alcohols is substantially greater than for the lower alcohols. This finding agrees with the cited model and suggests that lower alcohols are more suitable precursors for the formation of graphene sheets.

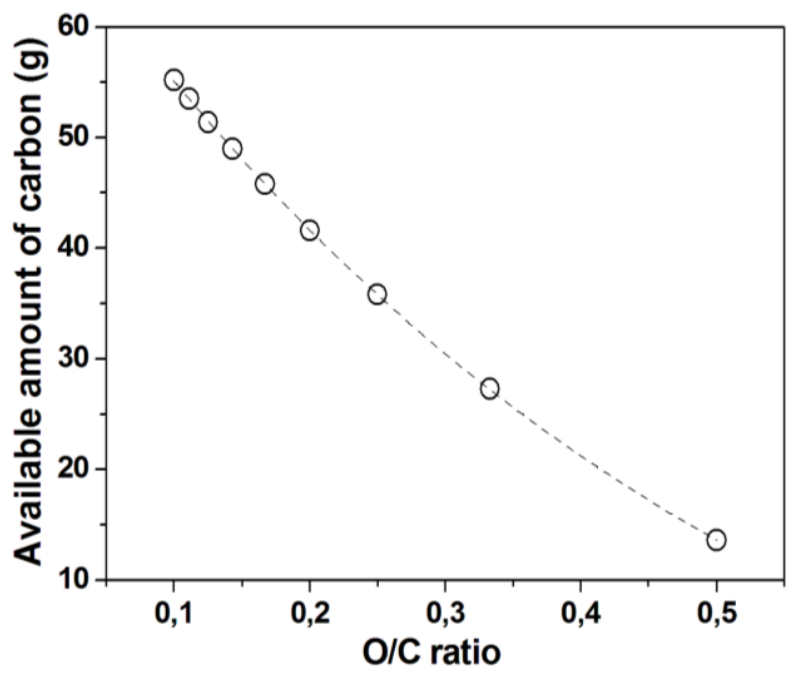

Figure 9. Available amount of carbon at $3000 \mathrm{~K}$ (starting amount of alcohol $100 \mathrm{~g}$ ). 


\subsection{Thermal stability of products}

The products were analyzed by thermogravimetry under $\mathrm{N}_{2} / \mathrm{O}_{2}$ atmosphere to evaluate their thermal stability. Figure10 presents three examples of the TGA curves acquired for the products obtained from decanol, ethanol and decanol with the addition of oxygen (5\%). A mass loss (10-15\%) between 200 and $400{ }^{\circ} \mathrm{C}$ is observed for all products. This loss is due to thermal decomposition of surface functional groups (for more details please see section 3.4) and desorption and/or thermal degradation of polycyclic aromatic hydrocarbons, e.g. naphtalene, anthracene and pyrene. These compounds frequently occur as the byproducts in carbon materials synthesized in thermal plasma systems [44-45].

The products start to combust over $400{ }^{\circ} \mathrm{C}$. The first derivative of the TGA curve shows several local maxima. Therefore, the deconvolution procedure using Lorentzian profiles has been carried out for each curve in order to evaluate the exact temperature (at which the gasification occurs with the highest rate) and relative areas. The deconvoluted curves along with the TGA data are shown in Figures S3-S13 (supplementary data). It can be seen that there are at least two profiles on each TGA curve. This suggests that the samples consist of carbon phases with different thermal stability. The thermal stability of carbon materials subjected to gasification is directly related to their particle size and their degree of graphitization. According to the core shrinking model the particles with smaller diameter or size start to oxidize at lower temperature [52]. Similarly, the particles of lower degree of graphitization also have lower resistance to combustion [53]. In reference to the presented TEM and SEM images the obtained products comprise of particles with different sizes and shapes, and this observation explains the differences in their thermal behavior. Nevertheless, the product from ethanol is composed of graphene flakes only. This result suggests that the product from ethanol should contain only one phase with the exact combustion temperature. However, the product from Test 9 contains flakes with various lateral size and thickness and 
this differentiation may affect the thermal behavior of this material. The temperature values evaluated from the deconvoluted curves are listed in Table 2. These data were divided into three groups, i.e. the first one which combusts with the highest rate at $550-600{ }^{\circ} \mathrm{C}$, the second one at $640-690{ }^{\circ} \mathrm{C}$ and the third group at $700-750{ }^{\circ} \mathrm{C}$. In the case of the product obtained from nonanol two phases combust in the temperatures assigned to the second phase. The relative contents of each phase were calculated from the areas of the deconvoluted first derivative and are shown in Figure 11. As it can be clearly seen, the most thermally stable phase ('third phase') is present in the products obtained from C2-C6 alcohols (Tests 5-9) and in the products when oxygen was added to the plasma gas (Tests 10-11). Importantly, in all these cases the oxygen to carbon ratio is higher than 0.167 . The amount of this 'third phase' is higher than $20 \%$ for the products obtained from ethanol, propanol and butanol (Tests 7-9). The products synthesized from the precursor having lower oxygen to carbon ratio (Tests 1-4) have lower resistance to oxidation, because the 'third phase' is absent. For all samples the amount of the least stable phase ('first phase') is higher than $40 \%$ and in most cases it is the dominant phase. The TGA data can be compared with the morphological studies presented above. The products obtained from higher alcohols have higher content of spherical particles which resemble carbon black. Carbon black is a material which is not completely amorphous, however, its degree of graphitization (and thermal resistance) is lower in comparison to graphite and few-layer graphene [53]. Therefore, the 'first phase' can be regarded as an quantitative indicator of the content of spherical particles in the products obtained from higher alcohols. 

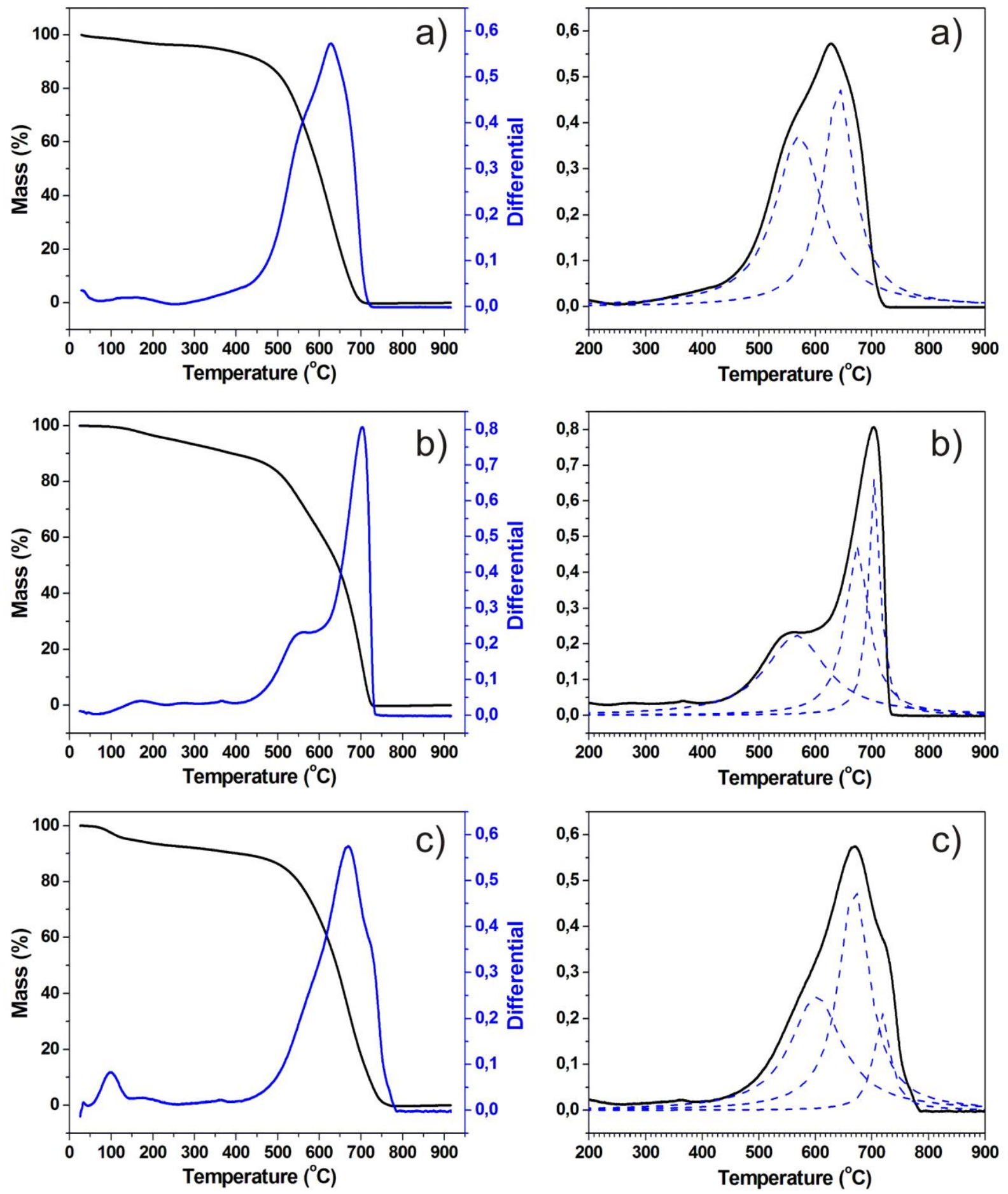

Figure 10. TGA curves and deconvoluted first derivatives for products obtained via plasma decomposition of a) decanol b) ethanol c) decanol with addition of 5\% of oxygen. 
Table 2. Properties of products investigated by TGA analysis.

\begin{tabular}{|l|l|l|l|l|}
\hline Test & Alcohol & \multicolumn{3}{|c|}{$\begin{array}{l}\text { Temperatures maxima } \\
\text { of differential curves }\left({ }^{\circ} \mathrm{C}\right)\end{array}$} \\
\hline 1 & decanol & 571 & 641 & \\
\hline 2 & nonanol & 579 & $680 ; 648$ & \\
\hline 3 & octanol & 564 & 646 & \\
\hline 4 & heptanol & 575 & 673 & \\
\hline 5 & hexanol & 557 & 657 & 736 \\
\hline 6 & pentanol & 578 & 666 & 720 \\
\hline 7 & butanol & 593 & 688 & 747 \\
\hline 8 & propanol & 597 & 681 & 716 \\
\hline 9 & ethanol & 566 & 674 & 704 \\
\hline 10 & decanol $\left(\mathrm{O}_{2} 1 \%\right)$ & 572 & 674 & 733 \\
\hline 11 & decanol $\left(\mathrm{O}_{2} 5 \%\right)$ & 601 & 669 & 718 \\
\hline
\end{tabular}

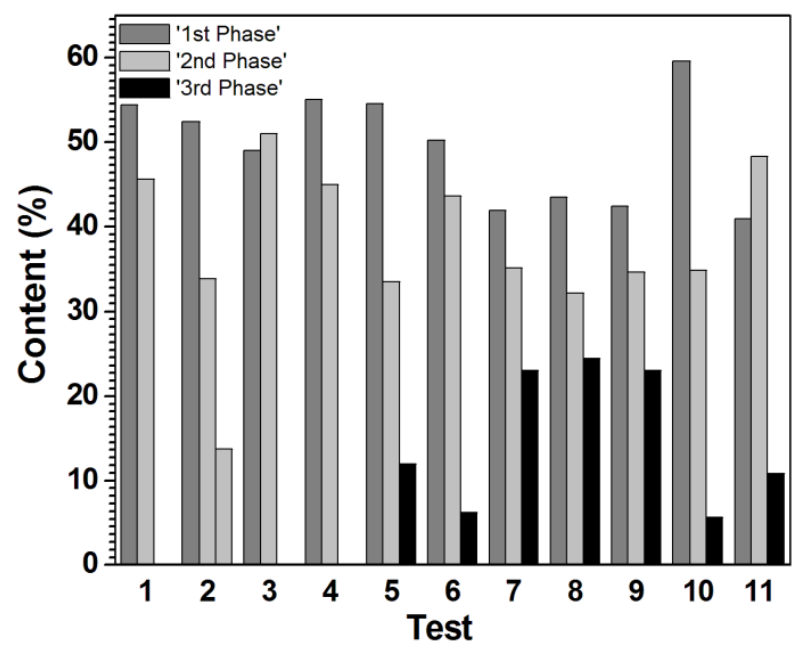

Figure 11. Relative content of carbon phases with different thermal stability.

\subsection{Structural features of products}

Raman spectroscopy is the most powerful tool to study the structural ordering of graphitic materials [54-56]. The Raman spectrum contains three typical bands: the G-band at ca. $1580 \mathrm{~cm}^{-1}$ which is related to the stretching vibrations, the D-band near $1350 \mathrm{~cm}^{-1}$ which is associated to the stacking disorder and defects in the carbon layer structure, and the second order feature (the 2D-band at ca. $2700 \mathrm{~cm}^{-1}$ ). The degree of graphitization is usually 
determined from the ratio between the integral intensity of the G-band and D-band. The higher the value of this factor, the greater the degree of graphitization is. The 2D-band is always stronger than the G-band in the case of monolayer graphene, however for the bilayer and few-layer graphene the 2D-band is weaker and broader than the G-band [55]. The fewlayer graphene materials always contain the 2D-band on the Raman spectrum and this feature can be used in order to distinguish few-layer graphene from carbon materials with very low degree of graphitization.

The Raman spectra of all products are presented in the supplementary data (Figure S14-S24). Figure 12 shows three representative spectra for the products obtained from ethanol and decanol without and with the inclusion of oxygen (5\%). These spectra are visibly different from each other. The spectrum for the product obtained from ethanol (Test 9) is characterized by a sharp G-band and a low intense D-band. In this case the ratio of area of Gband to D-band is 1.20 and is the highest among all studied products. This finding shows that the product obtained from ethanol has the largest degree of graphitization. There is no unambiguous linear trend between the oxygen to carbon ratio and the G/D ratio, however, the products obtained from higher alcohols have substantially lower degree of graphitization in comparison to the materials synthesized from lower alcohols. An interesting effect is observed for the tests with decanol. In this case the G/D ratio monotonically rises with the increase of the content of gaseous oxygen in the plasma gas (from 0.426 to 0.839 ; Tests 1,10 and 11). This finding shows that gaseous oxygen enhances the formation of more graphitized product and is in good agreement with the thermal stability studies. The amount of the 'first phase' in the products obtained from decanol also monotonically rises with the increase of the content of the added oxygen. Table 3 contains the determined G/D ratios for all samples. There are some values of this factor higher than 0.7 as mentioned earlier, for the products obtained from hexanol, butanol, propanol and ethanol. The 2D band is observed in the Raman spectra of all 
studied products. This shows that all products can be regarded as carbon materials having graphitic structure. The 2D/G band ratio in the materials synthesized from hexanol, butanol, propanol and ethanol is higher in comparison with other products. This observation again shows that higher oxygen to carbon ratio is necessary to obtain more graphitized product.

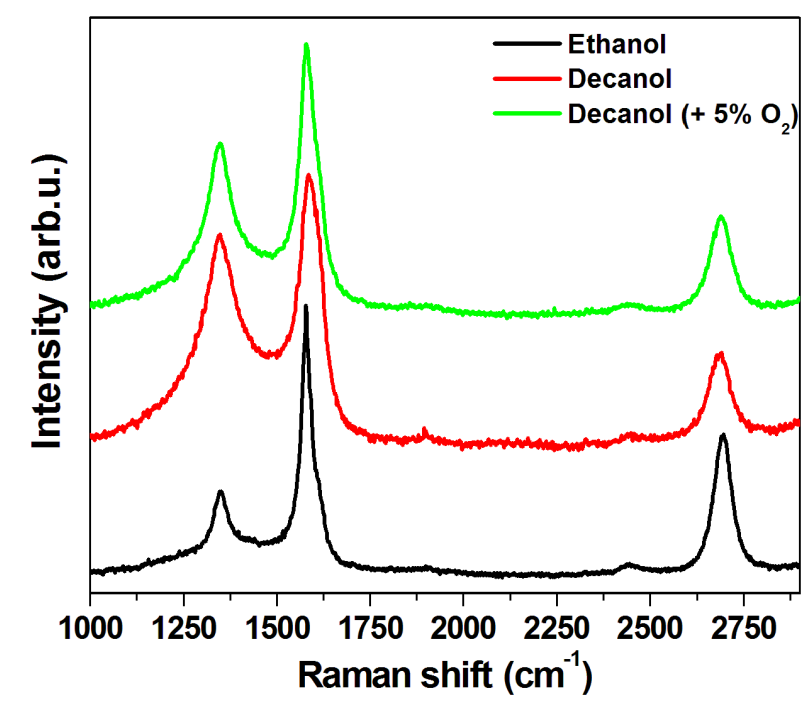

Figure 12. Representative Raman spectra for obtained products.

Table $3 \mathrm{G} / \mathrm{D}$ ratio for obtained products.

\begin{tabular}{|l|l|l|}
\hline Test & G/D & Alcohol \\
\hline 1 & 0.426 & decanol \\
\hline 2 & 0.593 & nonanol \\
\hline 3 & 0.555 & octanol \\
\hline 4 & 0.481 & heptanol \\
\hline 5 & 0.835 & hexanol \\
\hline 6 & 0.533 & pentanol \\
\hline 7 & 0.908 & butanol \\
\hline 8 & 0.747 & propanol \\
\hline 9 & 1.204 & ethanol \\
\hline 10 & 0.744 & decanol $\left(1 \% \mathrm{O}_{2}\right)$ \\
\hline 11 & 0.839 & decanol $\left(5 \% \mathrm{O}_{2}\right)$ \\
\hline
\end{tabular}

The plasma decomposition of alcohols yields particles which may have surface functional groups, because the precursors contain both oxygen and hydrogen. The presence of 
these groups can be tracked by IR spectroscopy (in a qualitative way [57-58]) and by acidbase titration (quantitative approach [Boehm 46-49]). Figure 13 shows the IR spectrum for the product obtained from ethanol. The spectra of other products are almost identical, therefore they are not included. The presented spectrum has a few characteristic bands. The strong and relatively broad band at $3575 \mathrm{~cm}^{-1}$ is attributed to hydroxyl groups (and adsorbed moisture). The bands located at $3115 \mathrm{~cm}^{-1}, 3035 \mathrm{~cm}^{-1}$ and the sharp and weak band at $2885 \mathrm{~cm}^{-1}$ are assigned to the presence of $\mathrm{C}-\mathrm{H}$ bonds, both aliphatic and aromatic. Therefore, it can be claimed that the obtained graphene sheets is partially hydrogenated. In fact, the hydrogenated graphene has been reported by Pumera et al. [58]. The sharp band at $1790 \mathrm{~cm}^{-1}$ originates from the $\mathrm{C}=\mathrm{O}$ bonds and is typical for carboxyl and ester groups. The two bands at $1500 \mathrm{~cm}^{-1}$ and $1410 \mathrm{~cm}^{-1}$ can be assigned to the $\mathrm{C}=\mathrm{C}$ skeletal vibration inside aromatic ring. The bands between 1000 and $700 \mathrm{~cm}^{-1}$ are typical for the bending C-H vibrations. Finally, a relatively weak band at $1180 \mathrm{~cm}^{-1}$ is related to single C-O bonds. Two sharp strong bands at $2375 \mathrm{~cm}^{-1}$ and $2310 \mathrm{~cm}^{-1}$ are caused by the presence of carbon dioxide. The above analysis shows that the produced carbon materials have various surface functional groups and their origin is connected with the chemical composition of the used precursors, i.e. aliphatic alcohols.

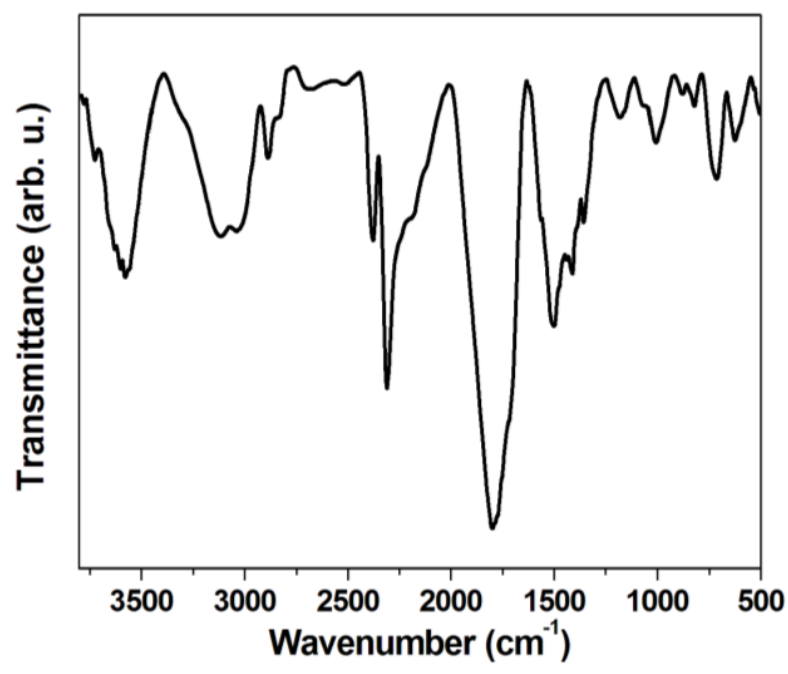

Figure 13. Infrared spectrum of the product obtained from ethanol. 
Boehm titration was carried out using $\mathrm{NaOH}$ and then the resulting surface acidity was evaluated. The surface acidity values (Table S1, see supplementary data) refer to the total content of carboxylic, lactonic and phenolic groups. The surface acidity varies between 0.28 and $1.35 \mathrm{mmol} \cdot \mathrm{g}^{-1}$. Figure 14 shows the correlation between the surface acidity and oxygen to carbon ratio. The curve shows that oxygen to carbon ratio is a parameter which strongly influences the surface acidity. The lowest content of acidic groups is found in the product obtained from pentanol, whilst the highest surface acidity belonged to the materials synthesized from ethanol and decanol. This pattern on the first look seems to be unusual, because from thermodynamic point of view the higher oxygen content in the reaction zone should result in product with larger content of surface acidic groups. However, one should take into account that the conditions in the plasma jet are very far from the thermodynamic equilibrium [44-45] because of the temperature gradient and the rapid quenching.

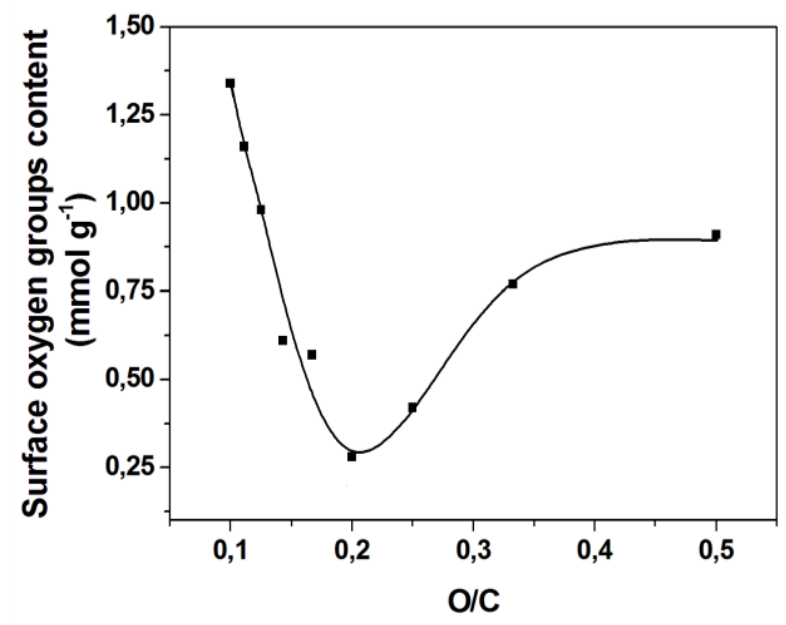

Figure 14. Relation between surface oxygen groups content and oxygen to carbon ratio in the case of alcohols thermal plasma decomposition (Tests 1-9). The solid curve is only to guide the eye. 
In the case of the plasma decomposition of decanol (Figure 15), the addition of $5 \%$ of gaseous oxygen results in decreasing the content of surface acidic groups (from 1.34 to 0.51 $\left.\mathrm{mmol} \cdot \mathrm{g}^{-1}\right)$, whilst in the case of $1 \%$ addition, the values are almost identical $\left(1.35 \mathrm{mmol} \cdot \mathrm{g}^{-1}\right)$. Hence, the direct inclusion of oxygen to the plasma gas also influences the surface acidity of the products in a different ways compared to pure alcohols. A as consequence, plausibly the direct inclusion of oxygen favors the combustion or gasification of products in the plasma jet instead of the oxidation of their surface.

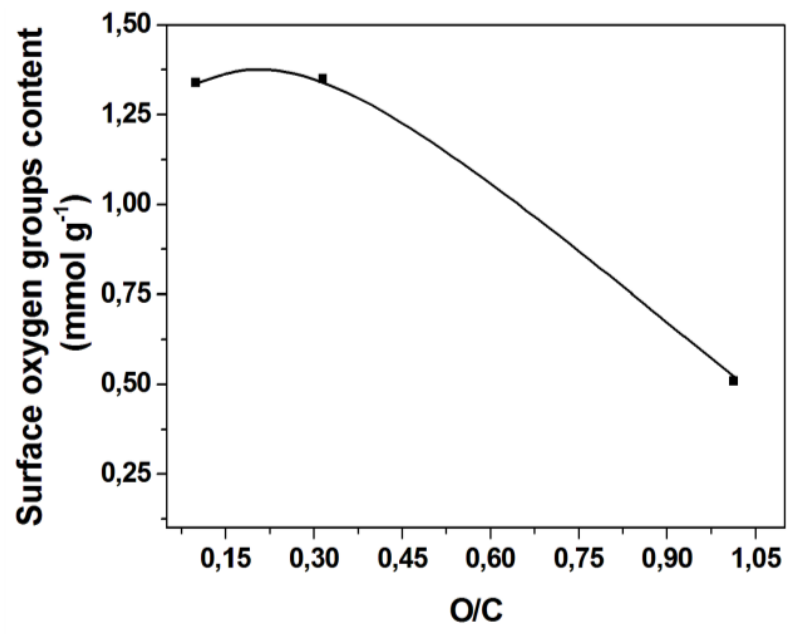

Figure 15. Relation between surface oxygen groups content and oxygen to carbon ratio in the case of thermal plasma decomposition of decanol (Test 1, 10 and 11). The solid curve is only to guide the eye.

Further details on the surface composition of the obtained materials were studied by X-ray photoelectron spectroscopy. The survey and C 1s core level spectra are shown in Figures S25-S36 in Supplementary Data. The survey spectra comprises only two components, i.e. the $\mathrm{C} 1 \mathrm{~s}$ and $\mathrm{O} 1 \mathrm{~s}$. The $\mathrm{O} 1 \mathrm{~s}$ peak frequently appears on the XPS spectra of various carbon materials and its presence is attributted to contaminations [60]. In fact, this feature was observed in the case of the spectrum of pure graphite (Figure S36). However, the relative area of the $\mathrm{O} 1 \mathrm{~s}$ peak for the studied materials is higher in comparison to graphite. This finding undoubtedly shows that oxygen is present in the obtained products. The $\mathrm{C} 1 \mathrm{~s}$ peak was 
analysed using a typical procedure, i.e. Shirley background subtraction and the deconvolution using using Voigt functions. The deconvoluted C 1s profiles comprises of three components centered at: $284.3 \mathrm{eV}, 284.5-284.7 \mathrm{eV}$ and $286.2-286.6 \mathrm{eV}$, which corresponds to $\mathrm{sp}^{2}, \mathrm{sp}^{3}$ and C-OH groups, respectively. The accurate energy of all peaks are listed in Table S2. Table 4 presents the chemical composition and the ratio between $\mathrm{sp}^{2}$ and $\mathrm{sp}^{3}$ carbons. The content of oxygen and carbon was calculated from the integral areas of $\mathrm{O} 1 \mathrm{~s}$ and $\mathrm{C} 1 \mathrm{~s}$ peaks. The $\mathrm{sp}^{2} / \mathrm{sp}^{3}$ ratio was determined from the deconvoluted $\mathrm{C}$ 1s profile. It can be seen that oxygen content decreases with the increase of the $\mathrm{O} / \mathrm{C}$ ratio. This change is accompanied by the increase of the content of carbon (Figures S37 and S38). There is also a monotonical dependence between the $\mathrm{sp}^{2} / \mathrm{sp}^{3}$ ratio and the $\mathrm{O} / \mathrm{C}$ factor (Figure S39). Hence, one can conclude that the products obtained at higher $\mathrm{O} / \mathrm{C}$ ratio are more graphitic than those synthesized from higher alcohols. This finding is in satisfactory agreement with the G/D ratio derived from the Raman spectra (Table 3).

The peak at 286.2-286.6 eV from the deconvoluted C1s component is present in all products (Table S2). As pointed out above this feature can be ascribed to $\mathrm{C}-\mathrm{OH}$ groups (phenolic or hydroxyl). The XPS spectra for lower alcohols (especially for ethanol) contain two broad peaks of very low intensity cententerd near 289 and $290 \mathrm{eV}$ (please see the inset in Figure S33). This feature can be attributted to carboxylic groups. To summarize, on the basis of the XPS analysis the $\mathrm{C}-\mathrm{OH}$ group is the major surface component in the products synthesized from aliphatic alcohols. This group is plausibly phenolicbecause of the results from Boehm titration, in which $\mathrm{NaOH}$ solution was used. The phenolic groups easily react with sodium hydroxide. The calculated surface acidity was used to estimate the oxygen content assuming that the molar mass of the $-\mathrm{OH}$ group is $17 \mathrm{mg} \cdot \mathrm{mmol}^{-1}$. The oxygen content was found to be between 0.36 and 1.73 at. \%. These values are in the same order as the oxygen content evaluated from the XPS spectra. 
Table 4. Chemical composition and $\mathrm{sp}^{2} / \mathrm{sp}^{3}$ ratio obtained from X-ray photoelectron spectra.

\begin{tabular}{|c|c|c|c|c|}
\hline Test & Precursor & $\begin{array}{c}\text { Content of oxygen } \\
(\% \text { at. }\end{array}$ & $\begin{array}{c}\text { Content of carbon } \\
(\% \text { at. })\end{array}$ & $\mathrm{sp}^{2} / \mathrm{sp}^{3}$ \\
\hline 1 & Decanol & 3.53 & 96.47 & 0.693 \\
\hline 2 & Nonanol & 3.53 & 96.47 & 0.922 \\
\hline 3 & Octanol & 3.61 & 96.39 & 0.441 \\
\hline 4 & Heptanol & 4.77 & 95.23 & 0.449 \\
\hline 5 & Hexanol & 3.24 & 96.76 & 0.695 \\
\hline 6 & Pentanol & 2.74 & 97.26 & 0.839 \\
\hline 7 & Butanol & 2.64 & 97.36 & 0.809 \\
\hline 8 & Propanol & 2.49 & 97.51 & 0.936 \\
\hline 9 & Ethanol & 1.62 & 98.38 & 1.216 \\
\hline 10 & Decanol $+1 \%$ O2 & 2.43 & 97.57 & 0.965 \\
\hline 11 & Decanol $+5 \%$ O2 & 1.66 & 98.34 & 1.538 \\
\hline- & Puregraphite & 1.01 & 98.99 & 2.404 \\
\hline
\end{tabular}

\subsection{Adsorption properties of products}

The adsorption properties of the products were investigated in a model process of the removal of 4-chlorophenol from water. Two working solutions of 4-chlorophenol $\left(50 \mathrm{mg} \cdot \mathrm{dm}^{-3}\right.$ and $100 \mathrm{mg} \cdot \mathrm{dm}^{-3}$ ) were chosen to determine the adsorption properties. The evaluated adsorption capacity values for these two concentrations are plotted in Figure 16. All studied materials have weak adsorption properties because the adsorption capacity does not exceed $10 \mathrm{mg} \cdot \mathrm{g}^{-1}$. The corresponding removal rate is found to be between 88 and $95 \%$. As for comparison the adsorption capacity for commercial activated carbon is $80 \mathrm{mg} \cdot \mathrm{g}^{-1}$ $\left(50 \mathrm{mg} \cdot \mathrm{dm}^{-3}\right)$ and $180 \mathrm{mg} \cdot \mathrm{g}^{-1}\left(100 \mathrm{mg} \cdot \mathrm{dm}^{-3}\right)$ [61]. The observed adsorption performance is typical for carbon materials having low porosity, e.g. carbon-encapsulated iron nanoparticles [61]. The direct comparison of adsorption capacity and surface acidity values (Table S1, see supplementary data) suggests that the presence of surface acidic groups does not favor the removal of 4-chlorophenol on the synthesized carbon materials. 


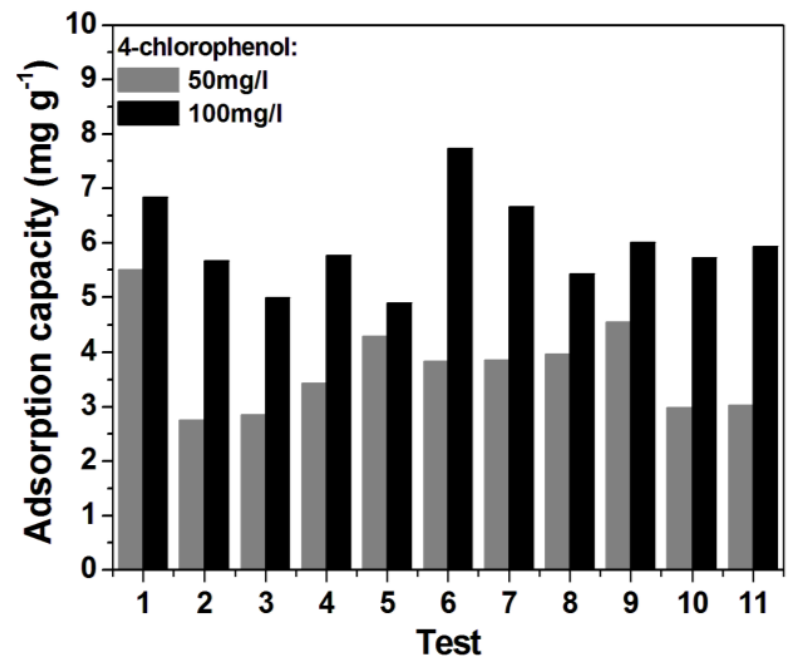

Figure 16. Adsorption properties of obtained products investigated by test with 4-chlorophenol.

\section{Conclusions}

A systematic study of thermal plasma processing of nine aliphatic alcohols (ethanoldecanol) has been performed in order to synthesis of graphene sheets. The inclusion of extra gaseous oxygen to the plasma gas has been also investigated. It has been found that the oxygen to carbon ratio is the key parameter which controls the conversion yield, product formation yield, morphology, thermal stability, degree of graphitization, $\mathrm{sp}^{2}$ to $\mathrm{sp}^{3}$ ratio, oxygen content and surface chemistry features. The products obtained from C3-C10 alcohols (propanol-decanol) were a mixture of flakes and spherical carbon nanoparticles. The addition of extra oxygen to the plasma jet slightly decreased the conversion yield and resulted in the formation of some amount of hollow highly graphitized carbon nanoparticles. The plasma processing of ethanol yielded a homogenous product which exclusively comprised of graphene sheets with the thickness between 3 and $10 \mathrm{~nm}$. The detailed analysis of TGA curves revealed that the products obtained from various alcohols have different behavior in terms of thermal oxidation stability. The degree of graphitization which was evaluated as the 
G/D ratio from the Raman spectra, followed the O/C ratio. The highest G/D ratio was found for the product obtained from ethanol. The products had very similar surface chemical characteristics with the dominant presence of $\mathrm{C}-\mathrm{O}, \mathrm{C}=\mathrm{O}$ and $\mathrm{C}-\mathrm{H}$ moieties. The surface acidity correlated with the $\mathrm{O} / \mathrm{C}$ ratio. The products had weak adsorption properties in the removal of 4-chlorophenol and their adsorption performance was comparable to other nonporous carbon nanomaterials. Finally, it has been demonstrated that pure graphene sheets can be selectively synthesized in the thermal plasma jet without any catalyst with the production rate of $1.5 \mathrm{~g} \cdot \mathrm{h}^{-1}$.

\section{Acknowledgments}

This work was supported by the National Centre for Research and Development (Poland) through the project LIDER 527/L-3-4/2012.

\section{References}

[1] Berger C, Song Z, Li T, Li X, Ogbazghi AY, Feng R et al. Ultrathin Epitaxial Graphite: 2D Electron Gas Properties and a Route toward Graphene-based Nanoelectronics. J Phys Chem B 108 (2004) 19912-19916

[2] Novoselov KS, Geim AK, Morozov SV, Jiang D, Zhang Y, Dubonos SV. Electric Field Effect in Atomically Thin Carbon Films. Science 306 (2004) 666-669

[3] Wada T, Yasutake T, Nakasuga A, Kinumoto T, Tsumura T, Toyoda M. Evaluation of Layered Graphene Prepared via Hydroxylation of Potassium-Graphite Intercalation Compounds. Journal of Nanomaterials (2014) article ID 925253

[4] Xu M, Sun H, Shen C, Yang S, Que W, Zhang Y et al. Lithium-assisted Exfoliation of Pristine Graphite for Few-later Graphene Nanosheets. Nano Res 8(3) (2015) $801-807$ 
[5] Subrahmanyam KS, Panchakarla LS, Govindaraj A, Rao CNR. Simple Method of Preparing Flakes by an Arc-Discharge Method. J Phys Chem C Lett 113 (2009) 4257-4259

[6] Wu Z-S, Ren W, Gao L, Zhao J, Chen Z, Liu B, et al. Synthesis of graphene sheets with high electrical conductivity and good thermal stability by hydrogen arc discharge exfoliation. ACS Nano 3(2) (2009) 411-7.

[7] Tkalya EE, Ghislandi M, de With G, Koning CE. The use of surfactants for dispersing carbon nanotubes and graphene to make conductive nanocomposites. Current Opinion in Colloid \& Interface Science 17 (2012) 225-232.

[8] Li C, Lv Q, Jiang D, Zhang L, Xia J, Li Q. Preparation of Nanosheets by Ultrasonic Exfoliation with the Aid of Surfactant Poly(vinylpyrrolidone). Chemistry Letters $41(2012) 732-734$.

[9] Łoś S, Duclaux L, Alvarez L, Hawełek Ł, Duber S, Kempiński W. Cleavage and size reduction of graphite crystal using ultrasound radiation. Carbon 55 (2013) 53 - 61.

[10] Wei Y, Sun Z. Liquid-phase exfoliation of graphite for mass production of pristine few-layer graphene. Current Opinion in Colloid \& Interface Science 20 (2015) 311321.

[11] Gao H, Zhu K, Hu G, Xue C. Large-scale graphene production by ultrasoundassisted exfoliation of natural graphite in supercritical $\mathrm{CO}_{2} / \mathrm{H}_{2} \mathrm{O}$ medium. Chemical Engineering Journal 308 (2017) 872-879.

[12] Strupiński W, Grodecki K, Wysmołek A, Stepniewski R, Szkopek T, Gaskell T et al. Graphene Epitaxy by Chemical Vapor Deposition on SiC. Nano Lett 11 (2011) 1786-1791.

[13] Grodecki K, Jóźwik I, Baranowski JM, Teklińska D, Strupiński W. SEM and Raman analysis of graphene on $\mathrm{SiC}$ (0001). Micron 80 (2016) 20-23. 
[14] Kaplas T, Kuzhir P. Ultrathin Graphitic Film: Synthesis and Physical Properties. Nanoscale 11 (2016) 54.

[15] Pei S, Cheng HM. The reduction of graphene oxide. Carbon 50 (2012) 32103228.

[16] Dercishi E, Li Z, Watanabe F, Biswas A, Xu Y, Biris AR et al. Large-scale graphene production by RF-cCVD method. Chem Comm (2009) 4061-4063.

[17] Dias FM, Bundaleska N, Henriques J, Tatarova E, Ferreira CM. Microwave plasma torches used for hydrogen production. J Phys: Conf Series 516 (2014) 012002.

[18] Kotov NA, Dekany I, Fendler JH, Ultrathin graphite oxide- polyelectrolyte composites prepared by self-assembly: transition between conductive and non-conductive states. Adv Mater 8(8) (1996) 637-641.

[19] Stankovich S, Piner RD, Chen X, Wu N, Nguyen ST, Ruoff RS. Stable aqueous dispersions of graphitic nanoplates via the reduction of exfoliated graphite oxide in the presence of poly(sodium 4-styrenesulfonate). J Mater Chem 16(2) (2006) 155-158.

[20] Li D, Muller MB, Gilje S, Kaner RB, Wallace GG. Processable aqueous dispersions of graphene nanosheets. Nat Nanotechnol 3(2) (2008) 101-105

[21] Zhou M, Wang Y, Zhai Y, Zhai J, Ren W, Wang F, et al. Controlled synthesis of large-area and patterned electrochemically reduced graphene oxide films. Chem Euro J 15(25) (2009) 6116-6120.

[22] Wang Z, Zhou X, Zhang J, Boey F, Zhang H. Direct Electrochemical reduction of single-layer graphene oxide and subsequent fictionalization with glucose oxidase. J Phys Chem C 113(32) (2009) 14071-14075. 
[23] An SJ, Zhu Y, Lee SH, Stoller MD, Emilsson T, Park S, et al. Thin film fabrication and simultaneous anodic reduction of deposited graphene oxide platelets by electrophoretic deposition. J Phys Chem Lett 1(8) (2010) 1259-1263.

[24] Ramesha GK, Sampath S. Electrochemical reduction of oriented graphene oxide films: an in situ Raman spectroelectrochemical study. J Phys Chem C 113(19) (2009) 79857989.

[25] McAllister MJ, Li J-L, Adamson DH, Schniepp HC, Abdala AA, Liu J, et al. Single sheet functionalized graphene by oxidation and thermal expansion of graphite. Chem Mater 19(18) (2007) 4396-4404.

[26] Lyth SM, Shao H, Liu J, Sasaki K, Akiba E. Hydrogen adsorption on graphene foam synthesized by combustion of sodium ethoxide. International Journal of Hydrogen Energy Volume 39(1) (2014) 376-380.

[27] Huczko A, Łabędź O, Dąbrowska A, Kurcz M, Bystrzejewski M, Lange H et al. Efficient one-pot synthesis of few-layered graphene. Physica Status Solidi B 252(11) (2015) 2412-2417.

[28] Huczko A, Kurcz M, Dąbrowska A, Fronczak M, Bystrzejewski M, Drozdowski M, et al. Synthesis of 3-D Graphene via combustion synthesis of magnesium and calcium/magnesium oxalates. ECS J. Solid State Sci. Technol. 6 (6) (2017) 3090-3096 .

[29] Nair RR, Wu HA, Jayaram PN, Grigorieva IV, Geim AK. Unimpeded Permeation of Water Through Helium-Leak-Tight Graphene-Based Membranes. Science 335 (2012) 442443.

[30] Wang X, Zhi L, Mullen K. Transparent, Conductive Graphene Electrodes for Dye-Sensitized Solar Cells. Nanoletters 8(1) (2008) 323-327. 
[31] Zheng D, Hu H, Liu X, Hu S. Application of graphene in electrochemical sensing. Current Opinion in Colloid \& Interface Science 20 (2015) 383-405.

[32] Bahadır EB, Sezgintürk MK. Applications of graphene in electrochemical sensing and biosensing. Trends in Analytical Chemistry 76 (2016) 1-14.

[33] Yuan W, Zhang Y, Cheng L, Wu H, Zheng L, Zhao D. The applications of carbon nanotubes and graphene in advanced rechargeable lithium batteries. J. Mater. Chem. A 4 (2016) 8932-8951.

[34] El-Kady MF, Ihns M, Li M, Hwang JY, Mousavi MF, Chaney L. Engineering three-dimensional hybrid supercapacitors and microsupercapacitors for high-performance integrated energy storage. PNAS 112(14) (2015) 4233-4238.

[35] Yang W, Ni M, Ren X, Tian Y, Li N, Su Y et al. Graphene in Supercapacitor Applications. Current Opinion in Colloid \& Interface Science 20 (2015) 416-428.

[36] Bystrzejewski M, Károly Z, Szépvölgyi J, Kaszuwara W, Huczko A, Lange H. Continuous synthesis of carbon-encapsulated magnetic nanoparticles with a minimum production of amorphous carbon. Carbon 47 (2009) 2040-2048.

[37] Bystrzejewski M, Károly Z, Szépvölgyi J, Huczko A, Lange H. Continuous synthesis of controlled size carbon-encapsulated iron nanoparticles. Mat Res Bulletin 46 (2011) 2408-2417.

[38] Rümmeli MH, Kramberger C, Grüneis A, Ayala P, Gemming T, Büchner B, Pichler T. On the Graphitization Nature of Oxides for the Formation of Carbon Nanostructures. Chem.Mater. 19(17) (2007) 4105-4107.

[39] Palacio R, Gallego J, Gabelica Z, Batiot-Dupeyrat C, Barrault J, Valange S. Decomposition of ethanol into $\mathrm{H} 2$-rich gas and carbon nanotubes over $\mathrm{Ni}$, $\mathrm{Co}$ and $\mathrm{Fe}$ supported on SBA-15 and Aerosil. Appl Cat A: General 504 (2015) 642-653. 
[40] Rincon R, Melero C, Jimenez M, Calzada MD. Synthesis of multi-layer graphene and multi-wall carbon nanotubes from direct decomposition of ethanol by microwave plasma without using metal catalysts. Plasma Sources Sci Technol 24 (2015) 032005.

[41] Amirov R, Shavelkina M, Alihanov N, Shkolnikov E, Tyuftyaev A, Vorobeva N. Direct Synthesis of Porous Multilayer Graphene Materials Using Thermal Plasma at Low Pressure. Journal of Nanomaterials (2015) article ID 724508.

[42] Dato A, Radmilovic V, Lee Z, Phillips J, Frenklach M Substrate-Free Gas-Phase Synthesis of Graphene Sheets. Nano Letters 8(7) (2008) 2012-2016

[43] Dato A, Frenklach M Substrate-free microwave synthesis of graphene: experimental conditions and hydrocarbon precursors. New Journal of Physics 12 (2010) 125013

[44] Fazekas P, Bódis E, Keszler AM, Cségény Z, Klébert S, Károly Z, Szépvölgyi. Decomposition of Chlorobenzene by Thermal Plasma Processing. J. Plasma Chem Plasma Process 33 (2013) 765-778.

[45] Fazekas P, Cségény Z, Mink J, Bódis E, Klébert S, Németh C, Keszler AM, Károly Z, Szépvölgyi J. Decomposition of poly(vinyl chloride) in inductively coupled radiofrequency thermal plasma. Chemical Engineering Journal 302 (2016) 163-171

[46] Boehm HP. Some aspects of the surface-chemistry of carbonblacks and other carbons. Carbon 32(5) (1994) 759-769.

[47] Boehm HP. Carbon surface chemistry. World Carbon; World of Carbon 1 (2001) $141-178$.

[48] Goertzen SL, Theriault KD, Oickle AM, Tarasuk AC, Andreas HA. Standarization of Boehm Titration: Part I. $\mathrm{CO}_{2}$ expulsion and endpoint determination. Carbon 48 (2010) 1252-1261. 
[49] Oickle AM, Goertzen SL, Hopper KR, Abdalla YO, Andreas HA. Standarization of Boehm Titration: Part II. Method of agitation, effect of filtering and dilute titrant Carbon 48 (2010) 3313-3322.

[50] Bystrzejewski M, Huczko A, Byszewski P, Domańska M, Rümmeli MH, Gemming T, Lange H. Systematic Studies on Carbon Nanotubes Synthesis from Aliphatic Alcohols by CVD Floating Catalyst Method Fullerenes. Nanotubes and Carbon Nanostructures. 17 (2009) 298-307.

[51] Frenklach M, Reaction mechanism of soot formation in flames. Physical Chemistry Chemical Physics 4 (2002) 2028-2037

[52] Mendiara T, Alzueta MU, Millera A, Bilbao R. Oxidation of Acetylene Soot: Influence of Oxygen Concentration. Energy Fuels. 21(6) (2007) 3208-3215

[53] Li Z, Zhang J, Li Y, Guan Y, Feng Z, Li C. Preparation and characterization of ordered mesoporous carbons on SBA-15 template. J. Mater. Chem., 16 (2006) 1350-1354

[54] Dresselhaus MS, Jorio A, Saito R. Characterizing Graphene, Graphite and Carbon Nanotubes by Raman Spectroscopy. Annu Rev Condens Matter Phys 1 (2010) 89-109.

[55] Ferrari AC, Meyer JC, Scardaci V, Casiraghi C, Lazzeri M, Mauri F et al. Raman Spectrum of Graphene and Graphene Layers. Phys Rev Lett 97 (2006) 187401.

[56] Drewniak S, Pustelny T, Pasternak I, Krajewska A, Konieczny G. Study of Morphology of Graphene using Atomic Force Microscopy and Raman Spectroscopy. Photonics Letters of Poland 6(4) (2014) 120-122.

[57] Kar T, Scheiner S, Adhikari U, Roy AK. Site Preferences of Carbohyl Groups on the Periphery of Graphene and Their Characteristic IR Spectra. J Phys Chem 117 (2013) $18206-18215$. 
[58] Kar T, Scheiner S, Patnaik SS, Bettinger HF, Roy AK. IR Characterization of Tip-Functionalized Single-Wall Carbon Nanotubes. J Phys Chem 11 (2010) 20955-20961.

[59] Pumera M, Hong An Wong C, Graphane and hydrogenated graphene. Chem. Soc. Rev.42 (2013) 5987-5995.

[60] Ferrah D, Penuelas J, Bottela C, Grenet G, Ouerghi A. X-ray photoelectron spectroscopy (XPS) and diffraction (XPD) study of a few layers of graphene on 6HSiC(0001). Surface Science Volume 615 (2013) 47-56.

[61] Strachowski P, Bystrzejewski M, Comparative studies of sorption of phenolic compounds onto carbon-encapsulated iron nanoparticles, carbon nanotubes and activated carbon. Coll Surf A: Physicochem. Eng Aspects 467 (2015) 113-123. 